\title{
EDITORIAL
}

\section{Acute vasodilator testing in idiopathic pulmonary arterial hypertension: must we take NO for the answer?}

\author{
C.F. Opitz* and L.J. Rubin ${ }^{\#}$
}

$\mathbf{T}$ he earliest clinical descriptions of primary pulmonary hypertension, now known as idiopathic pulmonary arterial hypertension (IPAH), were accompanied by the hypothesis that pulmonary vasoconstriction was one of its key pathophysiological elements [1] and that vasodilators could, therefore, be therapeutically useful. In support of this concept, DRESDALE et al. [2] first reported attenuation of pulmonary hypertension with the systemic vasodilator tolazoline, while HARRIS [3] and WOOD et al. [4] achieved more preferential pulmonary vasodilation with acetylcholine infused directly in the pulmonary artery. Only years later, when FURCHGOTT and ZAWADZKI [5] demonstrated that acetylcholine-induced vasodilation was mediated by nitric oxide (NO), an observation for which R.F. Furchgott shared the Nobel Prize in Medicine in 1998, was the importance of endothelial dysfunction in the pathogenesis of IPAH appreciated, and the rationale for testing acute vasoreactivity in IPAH using inhaled NO (iNO) or other endothelial-derived vasodilator substances established.

When RicH and BRUnDAGE [6] treated patients with high-dose calcium channel blockers (CCBs) in an attempt to reverse pulmonary vasoconstriction it became clear, however, that only a subgroup of IPAH patients responded with haemodynamic and clinical improvement. Furthermore, since it was impossible to identify a priori any clinical or haemodynamic predictors for a positive responder status, nonresponders were subjected both acutely and chronically to the risks of potent systemic vasodilator agents without any chance of benefit. Additionally, the criteria for "acute response" that was predictive of at least a reasonable chance of achieving a favourable long-term response to treatment with CCB was not clear until SiтBON et al. [7] retrospectively analysed their experience with acute vasodilator testing and long-term treatment with CCBs and suggested that a near normalisation of pulmonary haemodynamics in response to acute testing is needed in order to warrant consideration of long-term $\mathrm{CCB}$ therapy. This response, a fall in mean pulmonary artery pressure of $\geqslant 10 \mathrm{mmHg}$ to a level $<40 \mathrm{mmHg}$ with an

*DRK Kliniken Berlin Köpenick, Berlin, Germany. "University of California San Diego School of Medicine, La Jolla, CA, USA.

STATEMENT OF INTEREST: Statements of interest for both authors can be found at www.erj.ersjournals.com/misc/statements.dtl

CORRESPONDENCE: C.F. Optiz, Klinik für Innere Medizin, Schwerpunkt Kardiologie, DRK Kliniken Berlin Köpenick, Salvador-Allende-Straße 2-8, 12559 Berlin, Germany. Fax: 493030353321. E-mail: c.opitz@drk-kliniken-berlin.de unchanged or increased cardiac output and unchanged systemic blood pressure [8, 9], while fairly uncommon in IPAH ( $\sim 10 \%$ of patients) and almost unheard of in other forms of pulmonary arterial hypertension (PAH), is the criteria suggested in published guidelines for "positive" acute vasoreactivity testing, and should be met before CCBs are prescribed to treat $\mathrm{PAH}$.

The ideal drug to assess acute vasoreactivity should be potent, titratable, short acting and convenient to administer. It should also be widely available, making cost an important criterion, as well. Intravenous epoprostenol and adenosine, and iNO are the most widely used and extensively studied agents [10] and are recommended by current guidelines [9], but none of these drugs fully satisfies all of the aforementioned criteria. While iNO is the optimum drug with respect to pulmonary selectivity, ease of administration and pharmacological profile, it is expensive and its use requires dedicated and costly technical equipment, making it impractical for use outside of specialty centres in industrialised countries.

Epoprotenol (prostacyclin) i.v. is a potent pulmonary vasodilator that was among the first drugs used to assess pulmonary vasoreactivity [11]. The inhaled delivery of prostacyclin analogues minimises the systemic vasodilatory effects observed with i.v. administration and produces more preferential pulmonary effects akin to those observed with iNO [12]. Additionally, inhaled iloprost, a stable prostanoid analogue, produces both a more potent and prolonged selective pulmonary effect compared with iNO, lasting for $\sim 45 \mathrm{~min}$ with a peak effect observed after $15 \mathrm{~min}$ [13]. While inhaled iloprost is frequently used to assess pulmonary vasoreactivity [14], prospective data describing the sensitivity and specificity of iloprost inhalation in detecting IPAH patients that are candidates for long-term CCB therapy are lacking.

The first study to prospectively address this question in a sizable group of IPAH patients is published by JING et al. [15] in this issue of the European Respiratory Journal. They assessed the potential of inhaled iloprost in identifying acute vasodilator responders in a group of 74 Chinese IPAH patients and correlated these findings with the long-term outcome during CCB treatment. Adenosine was given i.v. as a reference vasodilator. Acutely, both drugs induced pulmonary vasodilation with a fall in pulmonary arterial pressure of $>10 \mathrm{mmHg}$ to $<40 \mathrm{mmHg}$ observed in 10 (14\%) patients following iloprost inhalation and eight $(11 \%)$ patients with adenosine infusion. All adenosine responders were identified with iloprost as well. Both iloprost and adenosine were well tolerated. Subsequently, 
nine of the 10 responders were successfully treated with a mean daily dose of $433 \mathrm{mg}$ diltiazem for $\geqslant 1 \mathrm{yr}$, with one patient lost to follow-up. Surprisingly, all of these nine responders showed sustained clinical improvement at $1 \mathrm{yr}$ with respect to functional class, dyspnoea score, walking distance and haemodynamic parameters. The authors concluded that inhaled iloprost represents an effective and safe screening agent to identify IPAH patients who might benefit from long-term CCB therapy.

When compared with the series of IPAH patients studied by SITBON et al. [7], the cohort by JING et al. [15] was younger ( $33 \pm 12$ versus $45 \pm 15$ yrs, including seven children) and less severely ill based on their 6-min walking distance (6MWD; $390 \pm 106$ versus $287 \pm 139 \mathrm{~m}$ ), functional class (New York Health Association class I-II 47\% versus 19\%) and haemodynamic data (mean right atrial pressure $5.3 \pm 5.1$ versus $10.0 \pm 5.0 \mathrm{mmHg})$. As in other series, the responders were younger (age $23 \pm 9 \mathrm{yrs}$ ) and less impaired (6MWD $438 \pm 80 \mathrm{~m}$ ) than nonresponders. Nevertheless, the acute responder rates of $13.5 \%$ with iloprost and $10.8 \%$ with adenosine, respectively, are almost identical to the rate of $12.6 \%$ reported by SITBON et al. [7]. In addition, the magnitude of the vasodilator effects achieved with iloprost and adenosine were comparable. As in other studies, the longer half-life of iloprost did not represent a clinically relevant disadvantage.

The study by JING et al. [15] supports the notion that inhaled iloprost effectively and safely identifies acute responders among patients with IPAH and that this acute response closely correlates with the long-term clinical efficacy of CCB therapy. However, differences between this and earlier studies $[7,16]$ with respect to the long-term response rates underscore the importance of careful clinical monitoring following the initiation of this therapy.

Although no direct comparisons are available, acute iloprost inhalation probably provides results that are clinically equivalent to those obtained with iNO, the current reference standard. Moreover, compared with iNO inhaled iloprost can be administered more conveniently and at a lower cost, making it particularly appealing for testing patients in areas with limited healthcare resources.

Almost half a century after the formulation of the vasoconstrictor hypothesis and initial vasodilator trials, it is now clear that, in most $\mathrm{PAH}$ patients, vasoconstriction plays a relatively minor pathogenic role and that vascular proliferation is our main therapeutic target. Accordingly, the treatment paradigm has shifted to drugs combining vasodilator with antiproliferative characteristics, including prostanoids [17], endothelin receptor antagonists [18] and phosphodiesterase inhibitors [19], all of which have shown efficacy in large-scale clinical trials. Accordingly, the value of acute vasoreactivity testing is two-fold: 1) to identify the small group of $\mathrm{PAH}$ patients who may benefit from less expensive simple vasodilator drugs such as CCB; and 2) to identify those in whom CCBs are not only unlikely to produce benefit, but their use will delay the initiation of more effective therapies for their condition. The work by JING et al. [15] provides new and important evidence that testing for acute vasoreactivity can be safely performed with less expensive and complex medications and that this approach provides meaningful data that physicians and patients can use in planning a long-term treatment strategy for this condition.

\section{REFERENCES}

1 Wood P. Primary pulmonary hypertension with special reference to the vasoconstrictive factor. Br Heart J 1958; 20: 557-570.

2 Dresdale DT, Michtom RJ, Schultz M. Recent studies in primary pulmonary hypertension, including pharmacodynamic observations on pulmonary vascular resistance. Bull N Y Acad Med 1954; 30: 195-207.

3 Harris P. Influence of acetylcholine on the pulmonary arterial pressure. Br Heart J 1957; 19: 272-278.

4 Wood P, Besterman EM, Towers MK, et al. The effect of acetylcholine on pulmonary vascular resistance and left atrial pressure in mitral stenosis. Br Heart J 1957; 19: 279-286.

5 Furchgott RF, Zawadzki JV. The obligatory role of endothelial cells in the relaxation of arterial smooth muscle by acetylcholine. Nature 1980; 288: 373-376.

6 Rich S, Brundage BH. High-dose calcium channel-blocking therapy for primary pulmonary hypertension: evidence for long-term reduction in pulmonary arterial pressure and regression of right ventricular hypertrophy. Circulation 1987; 76: 135-141.

7 Sitbon O, Humbert M, Jais X, et al. Long-term response to calcium channel blockers in idiopathic pulmonary arterial hypertension. Circulation 2005; 111: 3105-3111.

8 Barst R, McGoon M, Torbicki A, et al. Diagnosis and differential assessment of pulmonary arterial hypertension. J Am Coll Cardiol 2004; 43, 12: Suppl. 1, S40-S47.

9 Galie N, Torbicki A, Barst R, et al. Guidelines on diagnosis and treatment of pulmonary arterial hypertension. The Task Force on Diagnosis and Treatment of Pulmonary Arterial Hypertension of the European Society of Cardiology. Eur Heart J 2004; 25: 2243-2278.

10 Badesch BD, Abman SH, Ahearn GS, et al. Medical therapy for pulmonary arterial hypertension. ACCP evidencebased guidelines for clinical practice. Chest 2004; 126: 35S-62S.

11 Badesch DB, Abman SH, Ahearn GS, et al. Medical therapy for pulmonary arterial hypertension: ACCP evidencebased clinical practice guidelines. Chest 2004; 126: Suppl. 1 , 35S-62S.

12 Opitz CF, Wensel R, Bettmann M, et al. Assessment of the vasodilator response in primary pulmonary hypertension. Comparing prostacyclin and iloprost administered by either infusion or inhalation. Eur Heart J 2003; 24: 356-365.

13 Hoeper MM, Olschewski H, Ghofrani HA, et al. A comparison of the acute hemodynamic effects of inhaled nitric oxide and aerosolized iloprost in primary pulmonary hypertension. German PPH study group. J Am Coll Cardiol 2000; 35: 176-182.

14 Hoeper MM, Lee SH, Voswinckel R, et al. Complications of right heart catheterization procedures in patients with pulmonary hypertension in experienced centers. J Am Coll Cardiol 2006; 48: 2546-2552.

15 Jing Z-C, Jiang X, Han Z-Y, et al. Iloprost for pulmonary vasodilator testing in idiopathic pulmonary arterial hypertension. Eur Respir J 2009; 33: 1351-1357. 
16 Rich S, Kaufmann E, Levy PS. The effect of high doses of calcium-channel blockers on survival in primary pulmonary hypertension. N Engl J Med 1992; 327: 76-81.

17 Gomberg-Maitland M, Olschewski H. Prostacyclin therapies for the treatment of pulmonary arterial hypertension. Eur Respir J 2008; 31: 891-901.
18 Dupuis J, Hoeper MM. Endothelin receptor antagonists in pulmonary arterial hypertension. Eur Respir J 2008; 31: 407-415.

19 Wilkins MR, Wharton J, Grimminger F, et al. Phosphodiesterase inhibitors for the treatment of pulmonary hypertension. Eur Respir J 2008; 32: 198-209. 